\title{
Nonalcoholic fatty liver disease in lean subjects: is it all metabolic-associated fatty liver disease?
}

\author{
Mariana Verdelho Machado ${ }^{1,2}$ \\ 'Faculdade de Medicina, Universidade de Lisboa, Lisbon 1649-035, Portugal. \\ ${ }^{2}$ Gastroenterology Department, Hospital de Vila Franca de Xira, Lisbon 1649-035, Portugal.
}

Correspondence to: Prof. Mariana Verdelho Machado, Gastroenterology Department, Faculdade de Medicina, Universidade de Lisboa, Avenida Professor Egas Moniz, Lisbon 1649-035, Portugal. E-mail: mverdelhomachado@gmail.com

How to cite this article: Machado MV. Nonalcoholic fatty liver disease in lean subjects: is it all metabolic-associated fatty liver disease? Hepatoma Res 2020;6:84. http://dx.doi.org/10.20517/2394-5079.2020.90

Received: 25 Aug 2020 First Decision: 29 Sep 2020 Revised: 25 Oct 2020 Accepted: 5 Nov 2020 Published: 5 Dec 2020

Academic Editor: Stefano Bellentani Copy Editor: Cai-Hong Wang Production Editor: Jing Yu

\begin{abstract}
The epidemiology of nonalcoholic fatty liver disease goes hand-in-hand with the obesity pandemic. The pathogenesis of fatty liver has shifted from an hepatocentric view to an adipocentric view, in which the overloaded adipose tissue spills out lipids that spread to ectopic tissues and organs such as the liver, elicits inflammation, and changes its adipokines profile promoting insulin resistance and the metabolic syndrome. Up to $40 \%$ of nonalcoholic fatty liver disease (NAFLD) patients are not obese and up to $20 \%$ are actually lean. Furthermore roughly $10 \%$ of lean subjects have NAFLD. In fact, adiposopathy can occur in patients with normal weight, and it is associated with expansion of metabolically active visceral fat and a qualitatively different adipose tissue that becomes overwhelmed after challenged by a mildly positive energy balance. This defines the concept of personal fat threshold that when exceeded results in metabolic dysfunction. Overweight/obese persons have higher probability of exceeding that threshold, explaining why adiposopathy/metabolic syndrome/NAFLD is more frequent in the obese. In this article, the epidemiology, pathogenesis, and management of patients with lean NAFLD are reviewed with an emphasis on reconciling the concepts of NAFLD in its relationship with adiposity and of NAFLD in lean individuals.
\end{abstract}

Keywords: Lean nonalcoholic fatty liver disease, metabolically obese normal weight, visceral adipose tissue 


\section{INTRODUCTION}

Fatty liver disease is the most common liver disease worldwide ${ }^{[1]}$. The realization that liver steatosis may progress to cirrhosis is credited to the Austrian pathologist Carl von Rokitansky in mid-nineteenth century. Rokitansky also acknowledged that alcohol might not explain all types of fatty liver ${ }^{[2]}$. The link with obesity was well-established one century after, with the description of liver biopsies from 20 obese men by Zelman $^{[3]}$. The designation "nonalcoholic steatohepatitis" (NASH) was first proposed by Ludwig 40 years $\operatorname{ago}^{[4]}$, and the more general "nonalcoholic fatty liver disease (NAFLD)" roughly 20 years ago ${ }^{[5,6]}$. In 2020 , an international group of experts changed the designation to "metabolic dysfunction-associated fatty liver disease" (MAFLD), focusing on the positive association with the metabolic syndrome (MS) rather than the negative association with alcohol, while acknowledging the possible concomitance of metabolic and alcohol-associated liver disease, in the same patient ${ }^{[7]}$.

NAFLD goes hand-in-hand with obesity and its associated co-morbidities, particularly the MS and its components $^{[8]}$. The prevalence of both NAFLD and obesity are rising. Data from the Fifth National Health and Nutrition Examination Survey (NHANES), in the US, showed that in the late 1980s, the prevalence of obesity was $22 \%$ and of NAFLD $20 \%$, whereas currently, it is $39 \%$ and $32 \%$, respectively ${ }^{[9]}$. In fact, obesity increases the risk for NAFLD by 10 -fold ${ }^{[9]}$.

Not all patients with NAFLD are overweight or obese. In those patients, liver steatosis has been called "lean-NAFLD" Lean-NAFLD was first recognized in studies from Asia ${ }^{[10]}$, but it has gained relevance in Western populations as well ${ }^{[11]}$.

New diagnostic criteria for MAFLD in lean persons were proposed ${ }^{[7]}$, in which alcohol consumption is not an exclusion criteria, but requires, evidence of hepatic steatosis and the presence of at least 2 of the following metabolic abnormalities:

(1) Waist circumference (WC) $\geq 102$ and $88 \mathrm{~cm}$ in Caucasian men and women, respectively (or $\geq 90$ and $80 \mathrm{~cm}$ in Asian men and women, respectively);

(2) Blood pressure $\geq 130 / 85 \mathrm{mmHg}$ or specific drug treatment;

(3) Plasma triglycerides $\geq 150 \mathrm{mg} / \mathrm{dL}$ or specific drug treatment;

(4) Plasma high-density lipoprotein (HDL)-cholesterol $<40 \mathrm{mg} / \mathrm{dL}$ for men and $<50 \mathrm{mg} / \mathrm{dL}$ for women or specific drug treatment;

(5) Prediabetes (i.e., fasting glucose levels $100-125 \mathrm{mg} / \mathrm{dL}$, or 2-h post-load glucose levels $140-199 \mathrm{mg} / \mathrm{dL}$ or HbA1c 5.7\%-6.4\%);

(6) Homeostasis model assessment (HOMA) of insulin resistance score $\geq 2.5$;

(7) Plasma high-sensitivity C-reactive protein level $>2 \mathrm{mg} / \mathrm{L}$.

Research on lean-NAFLD is flourishing; however, many gaps in knowledge still subside: Does lean-NAFLD always associate with metabolic dysfunction and hence can be classified as MAFLD? Does lean-NAFLD follow the same fate as obesity-associated MAFLD? How should lean-NAFLD patients be managed? This article is a comprehensive review of the pathogenesis and clinical relevance of lean-NAFLD that aims to help clinicians in their daily practice.

\section{EPIDEMIOLOGY}

Roughly $20 \%$ of patients with hepatic steatosis present with normal body mass index (BMI) and $40 \%$ are not obese ${ }^{[12,13]}$. As such, lean-NAFLD represents a significant burden on the daily practice of hepatologists.

Epidemiological studies on lean-NAFLD present very heterogeneous data, which result from: (1) different populations with different adipose tissue compartmentalization; (2) different definitions of lean (some 
studies consider normal weight, others non-obese, while studies in rural populations in Asia include a high proportion of patients underweight ${ }^{[14]}$ ); and (3) different tools to diagnose liver steatosis. Most studies rely on ultrasound to diagnose NAFLD, which has very low sensitivity for mild steatosis; others take advantage of non-invasive scores such as fatty liver index, some quantify liver triglycerides content through magnetic resonance spectroscopy, and several rely on liver biopsies. Those different diagnostic tools have known variations in accuracies for detecting liver steatosis ${ }^{[15]}$.

Notably, epidemiological studies were performed before the new designation of MAFLD; as such, alcohol intake was excluded, and patients may not fulfill the diagnostic criteria of MAFLD. Because of this, the designation "lean NAFLD" is used in this review.

The definition of normal weight using BMI varies depending on the racial background of the individual. Caucasians are considered as having normal weight when BMI is $18.5-25 \mathrm{~kg} / \mathrm{m}^{2}$ with overweight being $25-$ $30 \mathrm{~kg} / \mathrm{m}^{2}$ and obese being $>30 \mathrm{~kg} / \mathrm{m}^{[2,16]}$. However, lower BMI cutoffs are applied to Asians because a specific BMI reflects a higher percentage of body fat and higher health risk compared to Caucasians ${ }^{[17]}$. Accordingly, in Asians, normal weight is considered when BMI is $<23 \mathrm{~kg} / \mathrm{m}^{2}$, with overweight being $23-25 \mathrm{~kg} / \mathrm{m}^{2}$ and obese being $>25 \mathrm{~kg} / \mathrm{m}^{[2,16]}$.

Although studies have shown a wide range of prevalence of NAFLD in lean individuals (from as low as $5 \%$ to as high as $26 \%$ ), two recent meta-analysis showed that roughly $10 \%$ of lean adults have NAFLD. The prevalence rises to $16 \%$ in non-obese adults ${ }^{[12,18]}$. Interestingly, the prevalence of lean-NAFLD gradually increased from $5.6 \%$ (95\%CI: $3.6-8.8$ ) in studies before 2000 to $12.6 \%$ (95\%CI: $8.8-17.9$ ) in studies after $2011^{[18]}$. The prevalence of NAFLD is around 4 times lower in the lean population compared to the overweight/obese population ${ }^{[11,19-24]}$. Asians seem to have a higher prevalence of lean-NAFLD, and African Americans lower ${ }^{[12,25]}$, which might be explained, at least to some extent, with different compartmentalization of fat depots and intrinsic differences in adipose tissue structure/function in individuals with different racial backgrounds ${ }^{[26]}$.

Regarding the association with metabolic features, lean patients with NAFLD seem to have an intermediate phenotype between healthy subjects and obese patients with MAFLD ${ }^{[12,18,27,28]}$, regarding glucose intolerance and insulin resistance (IR), type-2 diabetes mellitus (T2DM), hypertension, and hyperuricemia. The lipid profile, however, appears to be similar between lean and obese patients with NAFLD, with similar levels of total cholesterol and triglycerides, although lean patients tend to present higher levels of HDL cholesterol $^{[20,27,29,30]}$.

On the other hand, a risk factor for NAFLD in lean subjects seems to be - besides older age - the presence of MS components (which seems to have an even stronger impact than in obese) ${ }^{[31]}$. In particular, hypertriglyceridemia associates with a 2 -fold increased risk for hepatic steatosis in lean ${ }^{[10,27,32]}$. Furthermore, baseline hypertriglyceridemia or T2DM were predictors of incident lean-NAFLD in longitudinal studies ${ }^{[3-35]}$.

Even though they are in the normal weight range, history of weight gain over $10 \mathrm{~kg}$ since early adulthood increased the risk for NAFLD 2.5 -fold in lean individuals ${ }^{[21]}$. Furthermore, patients with lean-NAFLD tend to present higher BMI as compared to lean subjects without NAFLD ${ }^{[30]}$. Interestingly, a Japanese study showed a linear increase on the prevalence of NAFLD with increasing BMI, starting at $18 \mathrm{~kg} / \mathrm{m}^{2}$ until $28 \mathrm{~kg} / \mathrm{m}^{[2,21,36]}$. Similarly, two longitudinal community-based studies in non-obese subjects, from South Korea and Sri-Lanka, showed that body weight changes were indicators for the development or regression of ultrasound-defined NAFLD ${ }^{[33,35]}$. Apparently, the lower the body fat (excluding underweight), the lower is the susceptibility for developing NAFLD. 


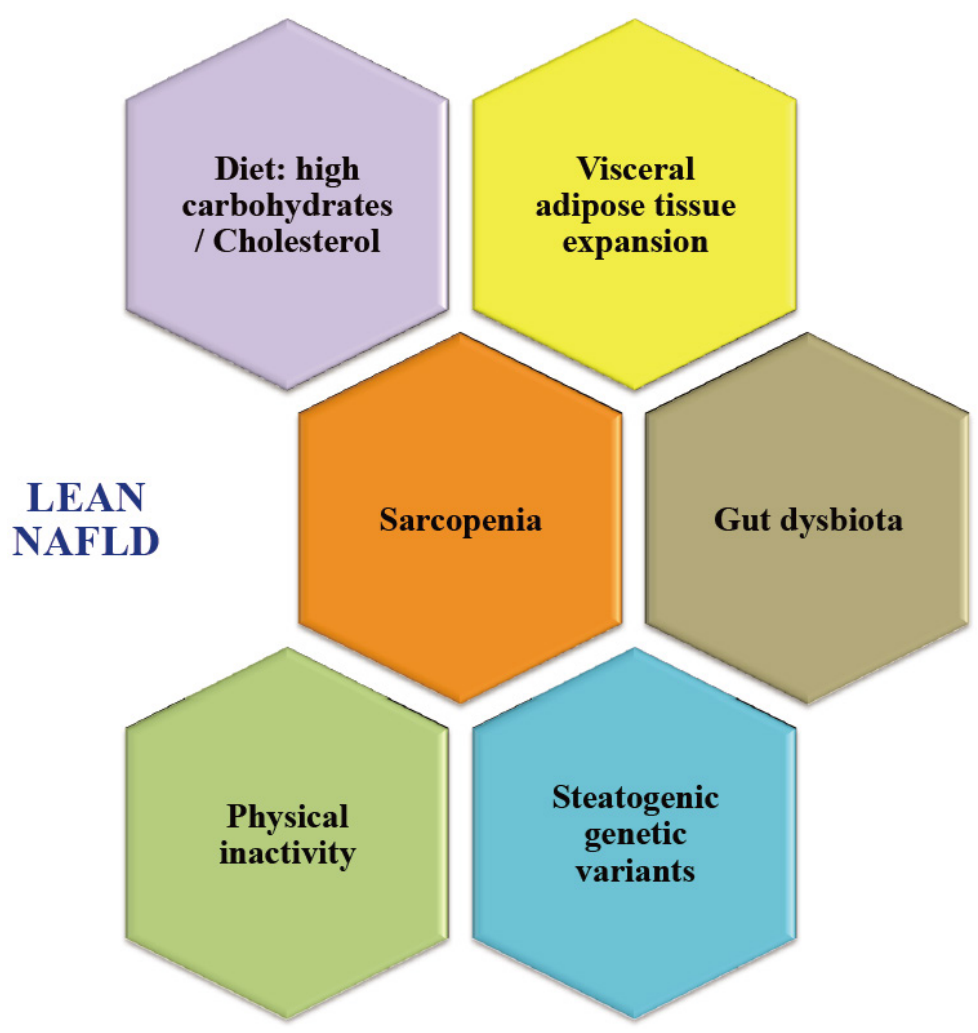

Figure 1. Pathogenesis of lean-NAFLD. NAFLD: nonalcoholic fatty liver disease

More important than BMI, a poor surrogate for adiposity, is central obesity which seems to predispose individuals to lean-NAFLD. In fact, lean patients with NAFLD tend to have higher WC as compared to lean subjects without NAFLD ${ }^{[32]}$. When comparing lean NAFLD with obese NAFLD, expectedly lean subjects present with lower WC. However, lean patients with NAFLD present similar waist-to-hip (WTH) ratio $^{[22]}$ but higher visceral adiposity indexes as compared to obese patients ${ }^{[20]}$. This can be explained by the poor accuracy of WC for visceral adipose tissue (VAT). In fact, WC is determined by both visceral and abdominal subcutaneous $\mathrm{fat}^{[37]}$.

Lastly, in lean individuals, higher ferritin and hemoglobin levels seem to be associated with NAFLD, which suggest iron overload and oxidative stress as a cofactor to lipotoxicity in this subset of patients ${ }^{[32,38]}$.

\section{PATHOPHYSIOLOGY}

Hepatic steatosis, in lean individuals, can be induced by different mechanisms [Figure 1]:

(1) The visceral adipose tissue spills over fatty acids that reach the liver, and promotes an inflammatory milieu, producing adipokines that are diabetogenic and steatogenic ${ }^{[39]}$;

(2) The liver itself is prone to steatosis, for example, as a consequence of genetic traits that modulate the metabolism and export of lipids ${ }^{[40]}$;

(3) Malnutrition and malabsorptive diseases induce hepatic steatosis ${ }^{[41,42]}$;

(4) The bowel induces hepatic steatosis through direct and indirect effects of a steatogenic and proinflammatory intestinal microbiota ${ }^{[43]}$;

(5) External factors induce hepatic steatosis such as drugs (for example, amiodarone, methotrexate, and tamoxifen);

(6) Other liver diseases may predispose to steatohepatitis (for example, hepatitis C particularly genotype 3 , Wilson's disease, and inborn errors of metabolism) ${ }^{[4]]}$. 
NAFLD is in intimate association with obesity and is characterized by features of adiposopathy ${ }^{[45]}$. However, adiposopathy may exist even with normal BMI, associating with an expansion of VAT, the socalled metabolically obese normal weight $(\mathrm{MONW})^{[46,47]}$. Adiposopathy may also occur in association with a lipodystrophic phenotype, which can be genetic (rare genetic lipodystrophy disorders have an estimated prevalence of one in a million ${ }^{[4]}$ ) or acquired [for example, an adverse effect of highly active antiretroviral therapy in patients infected with human immunodeficiency virus (HIV) $\left.{ }^{[39]}\right]$.

\section{Metabolically obese normal weight}

BMI is an imperfect measurement of obesity/adiposity because it does not take into consideration body composition (for example, differences in adipose and muscle mass), or the different patterns of fat distribution ${ }^{[49]}$. MONW refers to subjects with normal weight according to BMI, but with associated cardiometabolic abnormalities such as IR, altered lipid profile, and/or hypertension ${ }^{[50]}$. The estimated prevalence of MONW is around $20 \%$ in normal weight subjects ${ }^{[51]}$. The prevalence seems to gradually increase from Caucasians to African American, Hispanics, and Asians ${ }^{[50]}$. The prevalence of MONW increases with age and with increasing BMI, even in the normal range ${ }^{[50]}$. Importantly, MONW is associated with a 3 -fold increase in all-cause mortality, T2DM, and cardiovascular events, resembling obese or overweight subjects with associated metabolic dysfunction ${ }^{[48]}$. MONW might explain a high fraction of patients with lean-NAFLD ${ }^{[39]}$. The unsolved question is why normal weight patients develop metabolic features of overweight/obese patients. There seems to be a "personal fat threshold" independent of BMI, that when exceeded results in metabolic dysfunction ${ }^{[52]}$. In fact, MONW subjects may have normal body fat percentage, but different compartmentalization of fat, with central obesity, and particularly with increased visceral fat. Indeed, epidemiological studies demonstrate a strong association between the MONW phenotype and visceral adiposity ${ }^{[53]}$.

VAT, that is intra-abdominal adipose tissue, accounts for $7 \%-15 \%$ of total body fat ${ }^{[39]}$, and expands when subcutaneous adipose tissue (SAT) surpasses its capability to adapt to a positive caloric balance ${ }^{[54]}$. VAT is morphologically and metabolically distinct from SAT. Adipocytes in VAT respond to energy surplus with cell hypertrophy, with enlarged adipocytes presenting decreased ability to further store lipids, enhanced lipolytic response, and blunted insulin-inhibition of lipoprotein lipase, demonstrating adipose tissue $\mathrm{IR}^{[55]}$. Unlike abdominal SAT, VAT is drained by the portal vein which allows exposure of the liver directly to high concentrations of free fatty acids (FFA) and glycerol from oversized visceral adipocytes ${ }^{[54]}$. In fact, while in lean healthy subjects the VAT contributes to only 5-10\% of the FFA that reach the portal vein, in subjects with expanded VAT, its contribution can increase to $50 \%{ }^{[56]}$. FFAs that reach the liver contribute to the accumulation of ectopic fat in the liver and promote hepatic $\mathrm{IR}^{[57]}$. In the liver, FFAs activate nuclear receptors such as peroxisome proliferator activated receptor (PPAR)-a and hepatic nuclear factor, which profoundly modulate hepatic lipid metabolism, promoting the synthesis and export of triglycerides, and explaining the strong association between hypertriglyceridemia and NAFLD, particularly in lean$\operatorname{NAFLD~}^{[54]}$.

The oversized VAT is prone to cell death and inflammation with macrophage infiltration ${ }^{[58]}$, which are responsible for local deregulation of adipokine secretion - with increased production of tumor necrosis factor (TNF)-a and interleukin-6, and decreased production of the insulin-sensitizer and anti-inflammatory adiponectin - and a systemic metabolic inflammatory state, further exacerbating $\operatorname{IR}^{[59]}$.

Epidemiological studies showed that VAT was an independent risk factor for NAFLD, whereas BMI was not ${ }^{[60-65]}$. Furthermore, there seems to be a dose-response association between VAT and prevalence of NAFLD $^{[62]}$. In contrast, between SAT and NAFLD, a negative association was even described ${ }^{[61]}$. Similarly, longitudinal studies showed that VAT expansion was associated with incident NAFLD, whereas SAT expansion was associated with NAFLD regression ${ }^{[66]}$. 
Studies on lean-NAFLD showed similar associations between hepatic steatosis and both central obesity and visceral fat ${ }^{[20,29,67-69]}$. Interestingly, lean-NAFLD patients present lower levels of adiponectin than their lean healthy counterparts. Furthermore, even though lean-NAFLD patients tend to have lower levels of leptin compared to overweight/obese NAFLD patients, which translates to lower body fat, they have similar levels of adiponectin, suggesting similar adipose tissue malfunction and adiposopathy ${ }^{[28,68,70]}$.

The differentiation between upper and lower body fat has unraveled interesting new concepts on the metabolic consequences of body fat distribution ${ }^{[7]}$. SAT can be divided into upper body fat, which refers to abdominal subcutaneous fat, and lower body fat, which refers to gluteofemoral subcutaneous fat. Data from the Third NHANES, in the US, showed that normal weight subjects with upper body obesity (defined by an increased WTH ratio) had the highest all-cause mortality rate, more than doubling both normal weight and overweight/obese subjects without upper body obesity, and being matched only by overweight/obese that also had upper body obesity ${ }^{[72]}$. Unlike abdominal/upper body fat, femoral/lower body subcutaneous fat seems to be an independent protective factor for cardiometabolic diseases and mortality ${ }^{[71,73,74]}$. In fact, abdominal SC fat depots are physiologically different from femoral SC fat depots. Abdominal SAT demonstrates a rapid diet-derived fat uptake and high lipid turnover responsive to adrenergic activation. Femoral SAT, on the contrary, has a low lipid turnover and is more efficient in storing fat, mounting a hyperplasic response (recruiting new adipocytes from precursors rather than enlarging the adipocytes as occurs in abdominal SAT) to a caloric challeng $e^{[75]}$, and being less susceptible to inflammation ${ }^{[7]}$. Upper and lower body fat are under different epigenetic control of genes involved in adipocyte differentiation, with higher expression of TBX5 and HOXA5 in upper SAT and higher expression of HOTAIR in lower $\mathrm{SAT}^{[76]}$. Noteworthy, polymorphisms in genes that regulate adipocyte differentiation such as CCDC92, DNAH10, and L3MBTL3, associate with lower body fat, and paradoxically with IR, T2DM, and coronary heart disease. This suggests that subjects with predisposed limited storage capacity of peripheral adipose tissue, are more susceptible to IR and to cardiometabolic diseases ${ }^{[7]}$.

Concordant with a role of decreased lower body fat in the susceptibility to NAFLD in lean individuals, WC and WTH ratio are better predictors for incident lean-NAFLD as compared to $\mathrm{BMI}^{[34,78]}$.

\section{Sarcopenia}

Sarcopenia, that is, loss of skeletal muscle mass and function, seems to confer susceptibility to NAFLD ${ }^{[79]}$. Sarcopenia may help explain the occurrence of hepatic steatosis in patients with BMI within the normal range, since BMI cannot differentiate between fat deprived nor muscle mass deprived subjects.

Data from the Korean National Health and Nutrition Examination Survey (KNHANES) showed that sarcopenia associates with NAFLD and liver fibrosis, independent of obesity and $\operatorname{IR}^{[79]}$. Other studies and recent meta-analysis corroborated that data ${ }^{[80-85]}$. Furthermore, skeletal muscle mass seems to be lower in lean versus obese patients with NAFLD ${ }^{[86]}$.

The relationship between sarcopenia and metabolic dysfunction goes both ways. IR and chronic inflammation promotes myosteatosis ${ }^{[87]}$, which exacerbates muscle catabolism. On the other hand, sarcopenia (and disturbed myokines secretion) promotes IR and hepatic steatosis ${ }^{[88]}$.

IR and T2DM promote muscle depletion and dysfunction through several mechanisms: (1) FFAs released by an insulin resistant adipose tissue inhibit the growth hormone/insulin growth factor- 1 axis, decreasing its protective effect on muscle regeneration ${ }^{[89]}$; (2) myosteatosis associates with a blunted activation of muscle peroxisome proliferator-activated receptor gamma coactivator-1a and an increase in oxidative stress resulting in mitochondrial dysfunction ${ }^{[90]}$; and (3) an increase in gluconeogenesis drives proteolysis. Obesity and NAFLD associate with a small grade inflammatory state, with an increase in proinflammatory 
cytokines such as TNF-a and interleukin-6 that stimulate proteolysis/muscle catabolism further contributing to sarcopenia ${ }^{[91]}$.

On the other hand, myosteatosis induces IR through FFA modulation of p38 mitogen-activated protein kinase $^{[92]}$. The muscle is the primary organ responsible for insulin-mediated glucose disposal, hence a decrease in muscle mass translates in impaired glucose metabolism, with postprandial hyperglycemia ${ }^{[93]}$. Sarcopenia also decreases the tolerance to exercise, further decreasing energy expenditure, exacerbating energy surplus, and promoting weight gain and $\mathrm{IR}^{[94]}$.

Myokines also have an important role in the pathogenesis of NAFLD. Irisin is an exercise-inducible myokine that promotes transdifferentiation of white into brown adipose tissue, with upregulation of uncoupling proteins, resulting in an increase in heat production, energy expenditure, and weight loss ${ }^{[95]}$. In the liver, irisin has direct anti-steatogenic effects through activation of PPAR-a and upregulation of fibroblast growth factor (FGF)-2 ${ }^{[88]}$. Accordingly, a study in obese patients showed a negative correlation between irisin and hepatic steatosis severity ${ }^{[96]}$. Myostatin is a myokine whose expression is downregulated by exercise ${ }^{[97]}$. Myosin has a negative impact on sarcopenia, since it promotes proteolysis and inhibits muscle regeneration and function ${ }^{[98]}$. Myostatin also has metabolic actions, promoting adipose tissue expansion through direct effects on the adipose tissue and indirectly through downregulation of irisin ${ }^{[99,100]}$. Lastly, myostatin has fibrogenic properties through direct action on hepatic stellate cells ${ }^{[101]}$. Interestingly, myostatin levels correlate with liver steatosis in lean subjects ${ }^{[69]}$. Increased myostatin levels are also seen in end-stage liver disease ${ }^{[102]}$, and associate with mortality in patients with liver cirrhosis ${ }^{[103]}$.

Sarcopenia and expansion of VAT act synergistically in the pathogenesis and progression of NAFLD. In patients with NAFLD, a decrease in muscle mass and increase in VAT are associated with worsening of steatosis and, more importantly, progression of liver fibrosis ${ }^{[104]}$.

\section{Genetics}

In 2008, a genome wide association study unraveled a polymorphism in patatin-like phospholipase domaincontaining protein 3 (PNPLA3), rs738409 $\mathrm{C}>\mathrm{G}$, encoding the substitution of isoleucine for methionine at position 148 (I148M), which associates with increased risk for hepatic steatosis disconnected from obesity or the $\mathrm{MS}^{[105,106]}$. Subsequent studies found that polymorphism is also associated with steatohepatitis, advanced fibrosis. and progression to hepatocellular carcinoma ${ }^{[107-110]}$.

PNPLA3 (adiponutrin) is a membrane-bound protein highly expressed in the liver and adipose tissue, that regulates remodeling of lipid droplets on hepatocytes and hepatic stellate cells. Diet can modulate PNPLA3 expression. Carbohydrates upregulate ${ }^{[111,112]}$, whereas unsaturated fatty acids suppress PNPLA3 expression $^{[113]}$. The rs738409 variant results in the accumulation of a dysfunctional adiponutrin on lipid $\operatorname{droplets}^{[114]}$.

Regarding the role of PNPLA3 rs738409 on lean-NAFLD, studies consistently found an increased G allele frequency on lean-NAFLD patients as compared to lean healthy subjects, mirroring studies on MAFLD ${ }^{[28]}$. Some studies also found an increased G allele or GG phenotype in lean $v s$. obese NAFLD patients ${ }^{[22,35,115,116]}$, though not all studies reproduced those findings ${ }^{[28,34,86,117]}$. An Italian study, albeit did not find a difference between $G$ allele frequencies in lean or obese NAFLD, found that this variant is associated with disease severity (presence of steatohepatitis and significant fibrosis) only in lean patients ${ }^{[118]}$. Two meta-analyses failed to find a difference in $G$ allele between lean and obese patients with $\operatorname{NAFLD~}^{[12,18]}$, which indicates that variants in PNPLA3 might not be a major factor in the development of lean-NAFLD. Of note, Asian studies showed higher differences in the PNPLA3 variant in lean-NAFLD as opposed to overweight/obese NAFLD ${ }^{[19]}$, suggesting interplay between racial background and PNPLA3 phenotype in the development of lean-NAFLD. 
Transmembrane-6 superfamily-2 (TM6SF2) is another gene that regulates lipid metabolism and has been implicated on the pathogenesis of NAFLD. TM6SF2 modulates intestinal cholesterol absorption and clearance, hepatic cholesterol biosynthesis and secretion, as well as the flux of triglycerides from lipid droplets to the synthesis and secretion of very low-density lipoproteins (VLDL) from the liver ${ }^{[40,120]}$. A variant of TM6SF2, rs58542926 C>T, possesses a substitution of glutamate for lysine at position 167 (E167K), and is a loss-of-function variant that increases the risk of NAFLD and hepatocellular carcinoma, albeit decreasing circulating lipids and protecting from cardiovascular disease $\mathrm{e}^{[121-125]}$.

Regarding the association between TM6SF2 rs58542926 and lean-NAFLD, two studies found a higher prevalence of the $\mathrm{T}$ allele in lean compared to overweight/obese patients with NAFLD ${ }^{[118,126]}$. However, others could not reproduce those findings ${ }^{[28,117]}$.

Cholesteryl ester transfer protein mediates the exchange of triglycerides from triglycerides-rich lipoproteins to HDL, allowing reverse cholesterol transport from peripheral tissues back to the liver. Two variants, rs12447924 and rs12597002, are associated with NAFLD in lean individuals, but not obese individuals, in an Australian cohort ${ }^{[127]}$.

SREBP-2 regulates cholesterol biosynthesis, uptake, and excretion. The SREBP-2 polymorphism rs133291 is associated with increased risk of NAFLD and steatohepatitis in non-obese, non-diabetic patients without the MS, once again helping to explain a dissociation between NAFLD and metabolic disturbances and obesity $^{[128]}$.

Lastly, a variant in phosphatidylethenolamine $\mathrm{N}$-methyltransferase (PEMT), rs7946 C>T was associated with lean-NAFLD and unhealthy lipid profile with an increase in low-density lipoproteins (LDL) and a decrease in $\mathrm{HDL}^{[129,130]}$. PEMT catalyzes de novo synthesis of choline, which is required for the export of hepatic triglycerides as VLDL ${ }^{[131]}$. Accordingly, patients with lean-NAFLD have low hepatic PEMT expression $^{[132]}$.

It would be interesting to evaluate whether lean patients with NAFLD have an increased risk of carrying at least one of the above different risk alleles as compared to overweight/obese NAFLD.

\section{Microbiota}

Microbiota may have a strong role on the development of NAFLD in lean subjects. When comparing the microbiota from lean and overweight/obese patients, significant differences have been consistently reported $^{[43,126,133]}$.

A multicenter study recruited patients from Italy and Australia, and found that lean-NAFLD, compared to non-lean NAFLD and controls, had an altered fecal microbiota profile. Lean patients had enrichment of the genera Erysipelotrichaceae UCG-003, Ruminococcus, Clostridium sensu stricto 1, Romboutsia, and Ruminococcaceae UCG-008, and an impoverishment of Ruminiclostridium and Streptococcus, as compared to non-lean patients ${ }^{[126]}$. This microbiota profile of lean patients seems to promote the formation of bile acids, and hence to associate with increased levels of secondary bile-acids, as well as FGF-19. This increase in bile acids and FGF-19 could explain a metabolic adaptation to an obesogenic diet, promoting a peripheral increase in energy expenditure. On the other hand, as compared to healthy subjects, leanNAFLD patients showed impoverishment of species believed to be protective against hepatic steatosis such as Marvinbryantia and Christensellenaceae R7 group, and enrichment of Dorea species that have previously been associated with $\mathrm{NASH}^{[126]}$.

Other studies found impoverishment of potentially protective bacteria such as Faecalibacterium and Lactobacillus $^{[43]}$. Faecalibacterium prausnitzii are butyrate-producing bacteria with known immune- 
modulation and anti-inflammatory properties that have already been implicated in the pathogenesis of NAFLD $^{[134]}$.

A Japanese study also found that lean-NAFLD patients more frequently carry an HLA haplotype (HLA-B`54:01) that modulates gut microbiota towards an impoverishment of bacteria potentially protective against progression to cirrhosis, such as the phylum Vernucomicrobia and the genus Akkermansia ${ }^{[134,135]}$.

Another way gut dysbiosis can promote hepatic steatosis is through the enrichment of bacteria, such as Weissella confusa that can produce ethanol through the fermentation of glucose and fructose ${ }^{[136,137]}$. A first pass effect of ethanol in the liver would abrogate systemic metabolic effects in patients harboring ethanolproducing microorganisms in the gut.

Studies regarding the use of probiotics on NAFLD do not specifically evaluate lean patients, are small sized, use different combinations of probiotic agents, and do not evaluate hard outcomes such as liver biopsy. However, a recent meta-analysis suggests a benefit of probiotics in the treatment of patients with NAFLD, inducing an improvement in liver enzymes ${ }^{[138]}$.

\section{Lifestyle}

A South Korean study evaluated a cohort of patients from the KNHANES, and found a high carbohydrate energy ratio and lower than moderate-level physical activity to be predictors of lean-NAFLD ${ }^{[139]}$. Carbohydrates are known to downregulate PNPLA3, which may partially explain its steatogenic effect $^{[111,12]}$. A caveat of this finding is that the type of carbohydrates consumed in Asia, where rice is the major carbohydrate, is likely not the same as in Western populations, hence it is difficult to extrapolate these findings to non-Asians ${ }^{[139]}$. High fructose intake has also been associated with lean-NAFLD ${ }^{[140]}$. Lean patients that develop NAFLD consume more than double added sugar than lean subjects without NAFLD. Of note, most of the added sugar, in lean-NAFLD patients, comes from soft drinks and juices. Indeed, the prevalence of excessive soft drink consumers is 4 times as higher in lean-NAFLD patients than healthy lean subjects $^{[140]}$.

Lean-NAFLD patients tend to eat high-cholesterol diets. Both European and Asian cohorts showed lean-NAFLD patients to consume more cholesterol and less polyunsaturated fatty acids, as compared to healthy lean subjects, even without an excessive caloric intake ${ }^{[68,141]}$. Cholesterol has steatogenic effects, since it promotes fatty acids synthesis and de novo lipogenesis through activation of SREBP-1c and liver X-receptor-a ${ }^{[68]}$.

Even though lean-NAFLD patients by definition have normal weight, they tend to adopt an intermediate obesogenic lifestyle. In fact, lean subjects that gain weight, over $10 \mathrm{~kg}$, in their adulthood have a 2.5 fold increased risk of developing NAFLD, even when maintaining a normal BMI ${ }^{[21]}$. Probably in patients that develop NAFLD, those 10 extra kilograms surpass their "personal fat threshold" ${ }^{[52]}$ inducing adiposopathy and its associated comorbidities.

\section{Malabsorption}

NAFLD is the most frequent hepatic manifestation of small bowel diseases with malabsorption such as inflammatory bowel disease (IBD) and celiac disease. We must consider these diagnoses in patients with lean-NAFLD, since $3 \%$ of patients with NAFLD have underlying celiac disease, which is 3 times the overall prevalence of celiac disease ${ }^{[142-145]}$. If we consider lean-NAFLD, the prevalence of celiac disease raises to up to $15 \%{ }^{[144]}$.

Overall, the reported prevalence of hepatic steatosis in patients with IBD is roughly $40 \%{ }^{[146]}$. Also celiac disease patients, even when in a gluten-free diet, present 3 times higher prevalence of hepatic steatosis 
as compared to healthy matched controls ${ }^{[147,148]}$. Interestingly, the risk of hepatic steatosis in non-obese celiac disease patients was almost 6 times higher than in weight-matched controls ${ }^{[147]}$. It seems that the more severe the malabsorption the higher the risk of hepatic steatosis. Indeed, patients with IBD that are underweight have 4 times higher prevalence of hepatic steatosis (up to 85\%) than the ones with normal weight. Hepatomegaly, severity of steatosis, and elevation of aminotransferases are also more severe ${ }^{[41]}$.

One important mechanistic link between bowel diseases and NAFLD is gut dysbiosis and increased intestinal permeability that may promote steatosis and inflammation in the liver ${ }^{[149]}$. Furthermore, malnutrition might lead to an impaired function of liver mitochondria and a loss of peroxisomes, which are important to maintain the normal liver function ${ }^{[150]}$.

Lastly, intestinal failure/parenteral nutrition-associated fatty liver disease is a different entity, in which liver histology is characterized by steatosis (often microsteatosis) in association with cholestasis. This form of fatty liver disease is associated with rapid and frequent progression to steatohepatitis and end-stage liver failure. Mechanistically, it associates with choline deficiency, which impairs lipid metabolism resulting in reduced synthesis of phospholipids and reduced export of hepatic lipids ${ }^{[42]}$.

\section{Hepatic steatosis as a manifestation of other liver diseases}

NAFLD is more frequent in overweight/obese subjects as compared to lean subjects. Hence, other liver diseases that increase liver fat should be actively excluded in lean subjects who present with hepatic steatosis. Chronic viral hepatitis (particularly hepatitis $C$ virus genotype $3^{[151]}$ ) and Wilson's disease can present with liver steatosis. Celiac disease should be systematically excluded since the prevalence of celiac disease in lean-NAFLD can reach up to $15{ }^{[144]}$. Cystic fibrosis should also be investigated, particularly in young patients with history of recurrent infections.

Inborn errors of metabolism should be suspected in young patients with atypical facial appearance, low stature, severe metabolic derangements (such as severe hyper- or hypolipidemia, hypoglycemia, and metabolic acidosis), and other organs involvement, with particular attention for muscle abnormalities, kidney disease (particularly tubulopathy), cardiovascular, and neurological symptoms ${ }^{[44]}$.

Lysosomal acid lipase (LAL)-deficiency is a rare autosomal recessive lysosomal disease that can present in the adulthood. It manifests by hepatosplenomegaly, dyslipidemia, and hepatic steatosis ${ }^{[152]}$. Its clinical course is characterized by early onset atherosclerosis with severe cardiovascular disease, and rapidly progressive liver disease. Indeed, liver cirrhosis and end-stage liver disease may develop within 3 years of the clinical onset. Liver biopsy presents mixed macro- and microvesicular steatosis, and the presence of birefringent cholesteryl ester crystals is pathognomonic. Diagnosis can be made with determination of LAL activity in dry blood sample. Albeit a rare disease (estimated prevalence of 1:40000 to 1:300000), an enzyme replacement therapy (sebelipase-alpha) is available. As such, it is worthwhile to investigate LALdeficiency in young lean-NAFLD patients with severe hypercholesterolemia (LDL higher than $160 \mathrm{mg} / \mathrm{dL}$ or $130 \mathrm{mg} / \mathrm{dL}$ in patients taking lipid-lowering drugs; and HDL lower than $40 \mathrm{mg} / \mathrm{dL}$ in men and $50 \mathrm{mg} / \mathrm{dL}$ in women), with cryptogenic cirrhosis, or with liver biopsy that shows microvesicular steatosis ${ }^{[152]}$. In fact, one third of patients with microvesicular steatosis or cryptogenic cirrhosis may have LAL-deficiency ${ }^{[153]}$.

Glycogen storage diseases might be misdiagnosed as lean-NAFLD because glycogen and fat accumulation in the liver may be undistinguishable by ultrasonography ${ }^{[154]}$. Some types of glycogen storage diseases may present a milder phenotype that can manifest only in adulthood, particularly types I, III, VI and IX. Besides symptoms related to hypoglycemia, these diseases may present with hepatosplenomegaly, that can progress to liver cirrhosis, hyperlipidemia (particularly hypertriglyceridemia), recurrent infections, myopathy, and kidney affection with tubular dysfunction and Fanconi-Bickel syndrome ${ }^{[4]}$. 
Hypobetalipoproteinemia is a common autosomal dominant disease that is characterized by defective transport of triglycerides from the liver, causing intrahepatic accumulation. Mutations in ApoB and microsomal triglyceride transfer protein can induce hepatic steatosis ${ }^{[155]}$. Hypobetalipoproteinemia associates with hypotriglyceridemia, absence of cardiometabolic dysfunction/ $\mathrm{IR}^{[156]}$, severe forms of NAFLD, and even hepatocellular carcinoma ${ }^{[157]}$.

\section{CLINICAL FEATURES AND PROGNOSIS}

Patients with lean-NAFLD may present the whole spectrum of liver disease, from isolated steatosis to liver cirrhosis, hepatocellular carcinoma, and end-stage liver disease. Most epidemiological studies suggest that liver histology might be less severe in lean patients as compared to overweight/obese patients with NAFLD/ MAFLD $^{[12,117,118,158-160]}$. This finding, however, may be biased as clinicians might have a lower threshold to perform liver biopsy in lean patients with hepatic steatosis, in whom it may be clinically relevant to exclude other diseases. As such, liver biopsy may be performed in patients with milder forms of liver injury. In a community-based Hong Kong cohort, non-obese NAFLD presented lower liver stiffness (4.6 kPa vs. $5.6 \mathrm{kPa}$ ) despite similar intrahepatic triglycerides content. However, the percentage of advanced fibrosis, defined by liver stiffness $>9.6 \mathrm{kPa}$, was similar ${ }^{[22]}$. Indian studies also showed similar prevalence of steatohepatitis and advanced fibrosis in lean and overweight/obese NAFLD patients ${ }^{[30,161]}$. An Austrian study of 466 liver biopsies, on the contrary, found worse liver injury with more severe fibrosis and more prevalent cirrhosis in lean patients ${ }^{[162]}$.

Central obesity/VAT expansion was the most transversal risk factor for advanced fibrosis in different epidemiological studies on lean-NAFLD ${ }^{[118]}$. In fact, each $10-\mathrm{cm}^{2}$ increase in VAT is associated with a $20 \%$ increased risk for significant fibrosis ${ }^{[63]}$. Other risk factors seem to be T2DM, hypertriglyceridemia, hypertension ${ }^{[118]}$, and higher levels of hemoglobin (suggesting mild iron overload and hence increased oxidative stress $)^{[163,164]}$.

Lean subjects with NAFLD have a 3 -fold increased risk for incident T2DM, even in the absence of MS. The risk for de novo T2DM seems similar to overweight/obese NAFLD patients ${ }^{[23,24,165]}$.

An analysis of the Third NHANES, showed that compared to healthy lean subjects, lean patients with ultrasound-diagnosed NAFLD had a 50\% increase in all-cause mortality and over a two-fold increase in cardiovascular mortality ${ }^{[166]}$.

Three long-term follow-up studies evaluated the outcome of patients with biopsy-confirmed leanNAFLD $^{[117,160]}$, one of them was presented as a poster ${ }^{[158]}$. A recent meta-analysis including the 2 published studies suggested that lean-NAFLD patients had $28 \%$ and $78 \%$ lower odds of overall mortality and liverrelated mortality, respectively. However, the cardiovascular death rate was similar, compared to obese patients with MAFLD ${ }^{[12]}$. The Asian published study followed 307 NAFLD patients for up to 5 years and did not find a difference in clinical events between lean and non-lean. The majority of the events were cardiovascular. Only 6 deaths occurred, all of them in obese patients. Furthermore, relevant liver events were limited to 2 cases of hepatocellular carcinoma and one of liver failure, again all obese patients ${ }^{[117]}$. The European published study followed 646 patients for up to 20 years ${ }^{[160]}$. They found no difference on overall mortality in lean versus non-lean NAFLD patients, but lean patients presented an increased risk for severe liver disease compared to overweight and similar to risk compared to obese patients. Of note, 58\% of lean patients who developed severe liver disease had no or mild fibrosis (Fo-2) at baseline ${ }^{[160]}$. The unpublished study is an international cohort of 1,900 patients and found that even though lean-NAFLD patients had milder histology at baseline, they had lower liver-transplant free survival than non-lean patients. 


\section{MANAGEMENT}

The main treatment in MAFLD is lifestyle modification in order to lose weight targeting normal weight ${ }^{[167]}$. Lean-NAFLD patients already have normal weight, should weight loss be pursued? What would be the target weight loss?

Epidemiological studies taught us that even in the normal weight range, the lower the BMI, the lower the risk for NAFLD ${ }^{[21,36]}$. Also, lean patients with NAFLD frequently present with VAT expansion ${ }^{[20]}$. The concept that everyone has their own personal fat threshold ${ }^{[52]}$ suggests that weight loss decreasing adiposity below the fat threshold might be beneficial metabolically and to the liver. In fact, in a small study with 20 lean-NAFLD patients, any weight loss was associated with steatosis improvement, and being above 5\% corporal weight was associated with improvement in NAFLD activity score ${ }^{[168]}$.

Exercise should be highly encouraged. Exercise, particularly aerobic exercise, seems to preferentially target VAT over SAT ${ }^{[169]}$. Also a significant decrease in VAT can occur even without significant weight loss ${ }^{[170]}$. Patients should be advised to perform aerobic exercise below current recommendations for overweight/ obese, with at least 150 min per week of moderate intensity exercise (for example, brisk walking, light jogging, or stationary ergometer usage $)^{[171]}$.

Cardiometabolic risk factors should be aggressively treated. Of note, incretin-based therapy may be more effective in overweight/obese because it associates with weight $\operatorname{loss}^{[47]}$. On the contrary, thiazolidinediones promote adipocyte differentiation and fat cell hyperplasia in adipocytes in subcutaneous compartments, and may be more effective in MONW patients ${ }^{[58]}$.

Lastly, modulation of gut microbiota in the treatment of lean-NAFLD should be further explored, giving the known role of gut dysbiota in its pathogenesis.

\section{CONCLUSION}

Lean-NAFLD is a frequent condition in the daily practice of hepatologists. Efforts should be made to differentiate between lean MAFLD and other conditions that are also associated with hepatic steatosis, such as other liver diseases (for example, chronic viral hepatitis and Wilson's disease), small bowel diseases with malabsorption (for example, celiac disease and Crohn's disease), and inborn errors of metabolism (for example, LAL-deficiency).

Patients with lean MAFLD have a disorder of the adipose tissue, despite their normal weight. Each individual might have his own personal fat threshold that when exceeded results in adipose tissue malfunction, cardiometabolic disturbances, and ectopic fat accumulation in the liver. The personal fat threshold is dependent on the different compartmentalization of the adipose tissue (visceral vs. subcutaneous and upper $v s$. lower body fat) as well as intrinsic properties of the adipose tissue that allow it to deal with fat challenges (hypertrophic $v s$. hyperplasic responses to energy surplus).

Patients with lean-NAFLD/MAFLD can have the whole spectrum of liver disease from isolated steatosis to liver cirrhosis and end-stage liver disease. Although studies evaluating the prognosis of lean NAFLD/ MAFLD are scarce, lean patients probably do not have a more benign prognosis as overweight/obese patients.

Management of patients with lean NAFLD/MAFLD should follow the same principles as for non-lean patients. Lifestyle modifications should be advised in order to address visceral fat. Weight loss might be beneficial even in patients with normal BMI, for whom their personal fat threshold falls below the upper normal BMI cutoff. 


\section{DECLARATIONS}

\section{Authors' contributions}

The author contributed solely to the article.

\section{Availability of data and materials}

Not applicable.

\section{Financial support and sponsorship}

None.

\section{Conflicts of interest}

All authors declared that there are no conflicts of interest.

\section{Ethical approval and consent to participate}

Not applicable.

\section{Consent for publication}

Not applicable.

\section{Copyright}

(C) The Author(s) 2020.

\section{REFERENCES}

1. Younossi Z, Anstee QM, Marietti M, et al. Global burden of NAFLD and NASH: trends, predictions, risk factors and prevention. Nat Rev Gastroenterol Hepatol 2018;15:11-20.

2. Best CH, Hartroft WS, et al. Liver damage produced by feeding alcohol or sugar and its prevention by choline. Br Med J 1949;2:10026 , pl.

3. Zelman S. The liver in obesity. AMA Arch Intern Med 1952;90:141-56.

4. Ludwig J, Viggiano TR, McGill DB, Oh BJ. Nonalcoholic steatohepatitis: mayo clinic experiences with a hitherto unnamed disease. Mayo Clin Proc 1980;55:434-8.

5. Angulo P. Nonalcoholic fatty liver disease. N Engl J Med 2002;346:1221-31.

6. Clark JM, Brancati FL, Diehl AM. Nonalcoholic fatty liver disease. Gastroenterology 2002;122:1649-57.

7. Eslam M, Newsome PN, Sarin SK, et al. A new definition for metabolic dysfunction-associated fatty liver disease: an international expert consensus statement. $J$ Hepatol 2020;73:202-9.

8. Machado MV, Cortez-Pinto H. Management of fatty liver disease with the metabolic syndrome. Expert Rev Gastroenterol Hepatol 2014;8:487-500.

9. Younossi ZM, Stepanova M, Younossi Y, et al. Epidemiology of chronic liver diseases in the USA in the past three decades. Gut 2020;69:564-8.

10. Chen $\mathrm{CH}$, Huang MH, Yang JC, et al. Prevalence and risk factors of nonalcoholic fatty liver disease in an adult population of taiwan: metabolic significance of nonalcoholic fatty liver disease in nonobese adults. J Clin Gastroenterol 2006;40:745-52.

11. Younossi ZM, Stepanova M, Negro F, et al. Nonalcoholic fatty liver disease in lean individuals in the United States. Medicine (Baltimore) 2012;91:319-27.

12. Young S, Tariq R, Provenza J, et al. Prevalence and profile of nonalcoholic fatty liver disease in lean adults: systematic review and metaanalysis. Hepatol Commun 2020;4:953-72.

13. Ye Q, Zou B, Yeo YH, et al. Global prevalence, incidence, and outcomes of non-obese or lean non-alcoholic fatty liver disease: a systematic review and meta-analysis. Lancet Gastroenterol Hepatol 2020;5:739-52.

14. Das K, Das K, Mukherjee PS, et al. Nonobese population in a developing country has a high prevalence of nonalcoholic fatty liver and significant liver disease. Hepatology 2010;51:1593-602.

15. Machado MV, Cortez-Pinto H. Non-invasive diagnosis of non-alcoholic fatty liver disease. A critical appraisal. J Hepatol 2013;58:1007-19.

16. Weir CB, Jan A. BMI classification percentile and cut off points. StatPearls. Treasure Island (FL): StatPearls Publishing; 2020.

17. Consultation WHOE. Appropriate body-mass index for Asian populations and its implications for policy and intervention strategies. Lancet 2004;363:157-63.

18. Shi Y, Wang Q, Sun Y, et al. The prevalence of lean/nonobese nonalcoholic fatty liver disease: a systematic review and meta-analysis. $J$ Clin Gastroenterol 2020;54:378-87. 
19. Bellentani S, Saccoccio G, Masutti F, et al. Prevalence of and risk factors for hepatic steatosis in Northern Italy. Ann Intern Med 2000;132:112-7.

20. Feng RN, Du SS, Wang C, et al. Lean-non-alcoholic fatty liver disease increases risk for metabolic disorders in a normal weight Chinese population. World J Gastroenterol 2014;20:17932-40.

21. Nishioji K, Sumida Y, Kamaguchi M, et al. Prevalence of and risk factors for non-alcoholic fatty liver disease in a non-obese Japanese population, 2011-2012. J Gastroenterol 2015;50:95-108.

22. Wei JL, Leung JC, Loong TC, et al. Prevalence and severity of nonalcoholic fatty liver disease in non-obese patients: a population study using proton-magnetic resonance spectroscopy. Am J Gastroenterol 2015;110:1306-14; quiz 15.

23. Kim SS, Cho HJ, Kim HJ, et al. Nonalcoholic fatty liver disease as a sentinel marker for the development of diabetes mellitus in nonobese subjects. Dig Liver Dis 2018;50:370-7.

24. Sinn DH, Kang D, Cho SJ, et al. Lean non-alcoholic fatty liver disease and development of diabetes: a cohort study. Eur J Endocrinol 2019;181:185-92.

25. Browning JD, Szczepaniak LS, Dobbins R, et al. Prevalence of hepatic steatosis in an urban population in the United States: impact of ethnicity. Hepatology 2004;40:1387-95.

26. Alberti KG, Zimmet P, Shaw J, Group IDFETFC. The metabolic syndrome--a new worldwide definition. Lancet 2005;366:1059-62.

27. Sookoian S, Pirola CJ. Systematic review with meta-analysis: risk factors for non-alcoholic fatty liver disease suggest a shared altered metabolic and cardiovascular profile between lean and obese patients. Aliment Pharmacol Ther 2017;46:85-95.

28. Feldman A, Eder SK, Felder TK, et al. Clinical and metabolic characterization of lean caucasian subjects with non-alcoholic fatty liver. Am J Gastroenterol 2017;112:102-10.

29. Margariti E, Deutsch M, Manolakopoulos S, Papatheodoridis GV. Non-alcoholic fatty liver disease may develop in individuals with normal body mass index. Ann Gastroenterol 2012;25:45-51.

30. Kumar R, Rastogi A, Sharma MK, et al. Clinicopathological characteristics and metabolic profiles of non-alcoholic fatty liver disease in Indian patients with normal body mass index: do they differ from obese or overweight non-alcoholic fatty liver disease? Indian $J$ Endocrinol Metab 2013;17:665-71.

31. Kwon YM, Oh SW, Hwang SS, Lee C, Kwon H, Chung GE. Association of nonalcoholic fatty liver disease with components of metabolic syndrome according to body mass index in Korean adults. Am J Gastroenterol 2012;107:1852-8.

32. Xu C, Yu C, Ma H, Xu L, Miao M, Li Y. Prevalence and risk factors for the development of nonalcoholic fatty liver disease in a nonobese Chinese population: the Zhejiang Zhenhai Study. Am J Gastroenterol 2013;108:1299-304.

33. Kim NH, Kim JH, Kim YJ, et al. Clinical and metabolic factors associated with development and regression of nonalcoholic fatty liver disease in nonobese subjects. Liver Int 2014;34:604-11.

34. Wong VW, Wong GL, Yeung DK, et al. Incidence of non-alcoholic fatty liver disease in Hong Kong: a population study with paired proton-magnetic resonance spectroscopy. J Hepatol 2015;62:182-9.

35. Niriella MA, Kasturiratne A, Pathmeswaran A, et al. Lean non-alcoholic fatty liver disease (lean NAFLD): characteristics, metabolic outcomes and risk factors from a 7-year prospective, community cohort study from Sri Lanka. Hepatol Int 2019;13:314-22.

36. Li L, Liu DW, Yan HY, Wang ZY, Zhao SH, Wang B. Obesity is an independent risk factor for non-alcoholic fatty liver disease: evidence from a meta-analysis of 21 cohort studies. Obes Rev 2016;17:510-9.

37. Kumar R, Mohan S. Non-alcoholic fatty liver disease in lean subjects: characteristics and implications. J Clin Transl Hepatol 2017;5:216-23.

38. Bernhardt P, Kratzer W, Schmidberger J, Graeter T, Gruener B, Group ES. Laboratory parameters in lean NAFLD: comparison of subjects with lean NAFLD with obese subjects without hepatic steatosis. BMC Res Notes 2018;11:101.

39. Younes R, Bugianesi E. NASH in Lean Individuals. Semin Liver Dis 2019;39:86-95.

40. Trepo E, Valenti L. Update on NAFLD genetics: from new variants to the clinic. J Hepatol 2020;72:1196-209.

41. Adams LC, Lubbe F, Bressem K, Wagner M, Hamm B, Makowski MR. Non-alcoholic fatty liver disease in underweight patients with inflammatory bowel disease: a case-control study. PLoS One 2018;13:e0206450.

42. Buchman AL, Naini BV, Spilker B. The differentiation of intestinal-failure-associated liver disease from nonalcoholic fatty liver and nonalcoholic steatohepatitis. Semin Liver Dis 2017;37:33-44.

43. Duarte SMB, Stefano JT, Miele L, et al. Gut microbiome composition in lean patients with NASH is associated with liver damage independent of caloric intake: a prospective pilot study. Nutr Metab Cardiovasc Dis 2018;28:369-84.

44. Yildiz Y, Sivri HS. Inborn errors of metabolism in the differential diagnosis of fatty liver disease. Turk J Gastroenterol 2020;31:3-16.

45. Machado MV, Diehl AM. Pathogenesis of nonalcoholic steatohepatitis. Gastroenterology 2016;150:1769-77.

46. Ruderman NB, Schneider SH, Berchtold P. The "metabolically-obese" normal-weight individual. Am J Clin Nutr 1981;34:1617-21.

47. Stefan N, Schick F, Haring HU. Causes, characteristics, and consequences of metabolically unhealthy normal weight in humans. Cell Metab 2017;26:292-300.

48. Kramer CK, Zinman B, Retnakaran R. Are metabolically healthy overweight and obesity benign conditions? A systematic review and meta-analysis. Ann Intern Med 2013;159:758-69.

49. Rothman KJ. BMI-related errors in the measurement of obesity. Int J Obes (Lond) 2008;32 Suppl 3:S56-9.

50. Gujral UP, Vittinghoff E, Mongraw-Chaffin M, et al. Cardiometabolic abnormalities among normal-weight persons from five racial/ Ethnic Groups in the United States: a cross-sectional analysis of two cohort studies. Ann Intern Med 2017;166:628-36.

51. Wang B, Zhuang R, Luo X, et al. Prevalence of metabolically healthy obese and metabolically obese but normal weight in adults worldwide: a meta-analysis. Horm Metab Res 2015;47:839-45. 
52. Taylor R, Holman RR. Normal weight individuals who develop type 2 diabetes: the personal fat threshold. Clin Sci (Lond) 2015;128:405-10.

53. Du T, Yu X, Zhang J, Sun X. Lipid accumulation product and visceral adiposity index are effective markers for identifying the metabolically obese normal-weight phenotype. Acta Diabetol 2015;52:855-63.

54. Neeland IJ, Ross R, Despres JP, et al. Visceral and ectopic fat, atherosclerosis, and cardiometabolic disease: a position statement. Lancet Diabetes Endocrinol 2019;7:715-25.

55. Zierath JR, Livingston JN, Thorne A, et al. Regional difference in insulin inhibition of non-esterified fatty acid release from human adipocytes: relation to insulin receptor phosphorylation and intracellular signalling through the insulin receptor substrate-1 pathway. Diabetologia 1998;41:1343-54.

56. Nielsen S, Guo Z, Johnson CM, Hensrud DD, Jensen MD. Splanchnic lipolysis in human obesity. J Clin Invest 2004;113:1582-8.

57. Feng R, Luo C, Li C, et al. Free fatty acids profile among lean, overweight and obese non-alcoholic fatty liver disease patients: a case control study. Lipids Health Dis 2017;16:165.

58. Tchernof A, Despres JP. Pathophysiology of human visceral obesity: an update. Physiol Rev 2013;93:359-404.

59. Wensveen FM, Valentic S, Sestan M, Turk Wensveen T, Polic B. The "Big Bang" in obese fat: events initiating obesity-induced adipose tissue inflammation. Eur J Immunol 2015;45:2446-56.

60. Hamaguchi M, Kojima T, Itoh Y, et al. The severity of ultrasonographic findings in nonalcoholic fatty liver disease reflects the metabolic syndrome and visceral fat accumulation. Am J Gastroenterol 2007;102:2708-15.

61. Park BJ, Kim YJ, Kim DH, et al. Visceral adipose tissue area is an independent risk factor for hepatic steatosis. J Gastroenterol Hepatol 2008;23:900-7.

62. Chung GE, Kim D, Kwark MS, et al. Visceral adipose tissue area as an independent risk factor for elevated liver enzyme in nonalcoholic fatty liver disease. Medicine (Baltimore) 2015;94:e573.

63. Yu SJ, Kim W, Kim D, et al. Visceral obesity predicts significant fibrosis in patients with nonalcoholic fatty liver disease. Medicine (Baltimore) 2015;94:e2159.

64. Choe EY, Lee YH, Choi YJ, et al. Waist-to-calf circumstance ratio is an independent predictor of hepatic steatosis and fibrosis in patients with type 2 diabetes. J Gastroenterol Hepatol 2018;33:1082-91.

65. Kure T, Mawatari S, Imamura Y, et al. Nonalcoholic fatty liver disease is associated with both subcutaneous and visceral adiposity: a cross-sectional study. Medicine (Baltimore) 2019;98:e17879.

66. Kim D, Chung GE, Kwak MS, et al. Body fat distribution and risk of incident and regressed nonalcoholic fatty liver disease. Clin Gastroenterol Hepatol 2016;14:132-8.e4.

67. Kim HJ, Kim HJ, Lee KE, et al. Metabolic significance of nonalcoholic fatty liver disease in nonobese, nondiabetic adults. Arch Intern Med 2004;164:2169-75.

68. Yasutake K, Nakamuta M, Shima Y, et al. Nutritional investigation of non-obese patients with non-alcoholic fatty liver disease: the significance of dietary cholesterol. Scand J Gastroenterol 2009;44:471-7.

69. Shida T, Oshida N, Suzuki H, et al. Clinical and anthropometric characteristics of non-obese non-alcoholic fatty liver disease subjects in Japan. Hepatol Res 2020; doi: 10.1111/hepr.13543.

70. Nakamuta M, Kohjima M, Higuchi N, et al. The significance of differences in fatty acid metabolism between obese and non-obese patients with non-alcoholic fatty liver disease. Int J Mol Med 2008;22:663-7.

71. Karpe F, Pinnick KE. Biology of upper-body and lower-body adipose tissue--link to whole-body phenotypes. Nat Rev Endocrinol 2015;11:90-100.

72. Sahakyan KR, Somers VK, Rodriguez-Escudero JP, et al. Normal-weight central obesity: implications for total and cardiovascular mortality. Ann Intern Med 2015;163:827-35.

73. Snijder MB, Zimmet PZ, Visser M, Dekker JM, Seidell JC, Shaw JE. Independent and opposite associations of waist and hip circumferences with diabetes, hypertension and dyslipidemia: the AusDiab Study. Int J Obes Relat Metab Disord 2004;28:402-9.

74. Yusuf S, Hawken S, Ounpuu S, et al. Obesity and the risk of myocardial infarction in 27,000 participants from 52 countries: a casecontrol study. Lancet 2005;366:1640-9.

75. Tchoukalova YD, Votruba SB, Tchkonia T, Giorgadze N, Kirkland JL, Jensen MD. Regional differences in cellular mechanisms of adipose tissue gain with overfeeding. Proc Natl Acad Sci U S A 2010;107:18226-31.

76. Pinnick KE, Nicholson G, Manolopoulos KN, et al. Distinct developmental profile of lower-body adipose tissue defines resistance against obesity-associated metabolic complications. Diabetes 2014;63:3785-97.

77. Lotta LA, Gulati P, Day FR, et al. Integrative genomic analysis implicates limited peripheral adipose storage capacity in the pathogenesis of human insulin resistance. Nat Genet 2017;49:17-26.

78. Zheng RD, Chen ZR, Chen JN, Lu YH, Chen J. Role of body mass index, waist-to-height and waist-to-hip ratio in prediction of nonalcoholic fatty liver disease. Gastroenterol Res Pract 2012;2012:362147.

79. Lee YH, Kim SU, Song K, et al. Sarcopenia is associated with significant liver fibrosis independently of obesity and insulin resistance in nonalcoholic fatty liver disease: nationwide surveys (KNHANES 2008-2011). Hepatology 2016;63:776-86.

80. Hong HC, Hwang SY, Choi HY, et al. Relationship between sarcopenia and nonalcoholic fatty liver disease: the Korean sarcopenic obesity study. Hepatology 2014;59:1772-8.

81. Issa D, Alkhouri N, Tsien C, et al. Presence of sarcopenia (muscle wasting) in patients with nonalcoholic steatohepatitis. Hepatology 2014;60:428-9.

82. Koo BK, Kim D, Joo SK, et al. Sarcopenia is an independent risk factor for non-alcoholic steatohepatitis and significant fibrosis. $J$ 
Hepatol 2017;66:123-31.

83. Petta S, Ciminnisi S, Di Marco V, et al. Sarcopenia is associated with severe liver fibrosis in patients with non-alcoholic fatty liver disease. Aliment Pharmacol Ther 2017;45:510-8.

84. Yu R, Shi Q, Liu L, Chen L. Relationship of sarcopenia with steatohepatitis and advanced liver fibrosis in non-alcoholic fatty liver disease: a meta-analysis. BMC Gastroenterol 2018;18:51.

85. Cai C, Song X, Chen Y, Chen X, Yu C. Relationship between relative skeletal muscle mass and nonalcoholic fatty liver disease: a systematic review and meta-analysis. Hepatol Int 2020;14:115-26.

86. Tobari M, Hashimoto E, Taniai M, et al. Characteristics of non-alcoholic steatohepatitis among lean patients in Japan: Not uncommon and not always benign. $J$ Gastroenterol Hepatol 2019;34:1404-10.

87. Machado MV, Ferreira DM, Castro RE, et al. Liver and muscle in morbid obesity: the interplay of fatty liver and insulin resistance. PLoS One 2012;7:e31738.

88. Bhanji RA, Narayanan P, Allen AM, Malhi H, Watt KD. Sarcopenia in hiding: the risk and consequence of underestimating muscle dysfunction in nonalcoholic steatohepatitis. Hepatology 2017;66:2055-65.

89. Kalyani RR, Corriere M, Ferrucci L. Age-related and disease-related muscle loss: the effect of diabetes, obesity, and other diseases. Lancet Diabetes Endocrinol 2014;2:819-29.

90. Hernandez-Alvarez MI, Thabit H, Burns N, et al. Subjects with early-onset type 2 diabetes show defective activation of the skeletal muscle PGC-1 \{alpha\}/Mitofusin-2 regulatory pathway in response to physical activity. Diabetes Care 2010;33:645-51.

91. Phillips T, Leeuwenburgh C. Muscle fiber specific apoptosis and TNF-alpha signaling in sarcopenia are attenuated by life-long calorie restriction. FASEB J 2005; 19:668-70.

92. Rubio-Ruiz ME, Guarner-Lans V, Perez-Torres I, Soto ME. Mechanisms underlying metabolic syndrome-related sarcopenia and possible therapeutic measures. Int J Mol Sci 2019;20:647.

93. Defronzo RA. Banting Lecture. From the triumvirate to the ominous octet: a new paradigm for the treatment of type 2 diabetes mellitus. Diabetes 2009;58:773-95.

94. Kim TN, Yang SJ, Yoo HJ, et al. Prevalence of sarcopenia and sarcopenic obesity in Korean adults: the Korean sarcopenic obesity study. Int J Obes (Lond) 2009;33:885-92.

95. Bostrom P, Wu J, Jedrychowski MP, et al. A PGC1-alpha-dependent myokine that drives brown-fat-like development of white fat and thermogenesis. Nature 2012;481:463-8.

96. Zhang HJ, Zhang XF, Ma ZM, et al. Irisin is inversely associated with intrahepatic triglyceride contents in obese adults. $J$ Hepatol 2013;59:557-62.

97. Huh JY. The role of exercise-induced myokines in regulating metabolism. Arch Pharm Res 2018;41:14-29.

98. Han HQ, Zhou X, Mitch WE, Goldberg AL. Myostatin/activin pathway antagonism: molecular basis and therapeutic potential. Int $J$ Biochem Cell Biol 2013;45:2333-47.

99. Li F, Li Y, Duan Y, Hu CA, Tang Y, Yin Y. Myokines and adipokines: Involvement in the crosstalk between skeletal muscle and adipose tissue. Cytokine Growth Factor Rev 2017;33:73-82.

100. Konopka AR, Wolff CA, Suer MK, Harber MP. Relationship between intermuscular adipose tissue infiltration and myostatin before and after aerobic exercise training. Am J Physiol Regul Integr Comp Physiol 2018;315:R461-8.

101. Delogu W, Caligiuri A, Provenzano A, et al. Myostatin regulates the fibrogenic phenotype of hepatic stellate cells via c-jun N-terminal kinase activation. Dig Liver Dis 2019;51:1400-8.

102. Garcia PS, Cabbabe A, Kambadur R, Nicholas G, Csete M. Brief-reports: elevated myostatin levels in patients with liver disease: a potential contributor to skeletal muscle wasting. Anesth Analg 2010;111:707-9.

103. Nishikawa H, Enomoto H, Ishii A, et al. Elevated serum myostatin level is associated with worse survival in patients with liver cirrhosis. J Cachexia Sarcopenia Muscle 2017;8:915-25.

104. Shida T, Oshida N, Oh S, Okada K, Shoda J. Progressive reduction in skeletal muscle mass to visceral fat area ratio is associated with a worsening of the hepatic conditions of non-alcoholic fatty liver disease. Diabetes Metab Syndr Obes 2019;12:495-503.

105. Romeo S, Kozlitina J, Xing C, et al. Genetic variation in PNPLA3 confers susceptibility to nonalcoholic fatty liver disease. Nat Genet 2008;40:1461-5.

106. Speliotes EK, Butler JL, Palmer CD, et al. PNPLA3 variants specifically confer increased risk for histologic nonalcoholic fatty liver disease but not metabolic disease. Hepatology 2010;52:904-12.

107. Rotman Y, Koh C, Zmuda JM, Kleiner DE, Liang TJ, Nash CRN. The association of genetic variability in patatin-like phospholipase domain-containing protein 3 (PNPLA3) with histological severity of nonalcoholic fatty liver disease. Hepatology 2010;52:894-903.

108. Valenti L, Al-Serri A, Daly AK, et al. Homozygosity for the patatin-like phospholipase-3/adiponutrin I148M polymorphism influences liver fibrosis in patients with nonalcoholic fatty liver disease. Hepatology 2010;51:1209-17.

109. Sookoian S, Pirola CJ. Meta-analysis of the influence of I148M variant of patatin-like phospholipase domain containing 3 gene (PNPLA3) on the susceptibility and histological severity of nonalcoholic fatty liver disease. Hepatology 2011;53:1883-94.

110. Liu YL, Patman GL, Leathart JB, et al. Carriage of the PNPLA3 rs $738409 \mathrm{C}>\mathrm{G}$ polymorphism confers an increased risk of non-alcoholic fatty liver disease associated hepatocellular carcinoma. J Hepatol 2014;61:75-81.

111. Dubuquoy C, Robichon C, Lasnier F, et al. Distinct regulation of adiponutrin/PNPLA3 gene expression by the transcription factors ChREBP and SREBP1c in mouse and human hepatocytes. J Hepatol 2011;55:145-53.

112. Huang Y, He S, Li JZ, et al. A feed-forward loop amplifies nutritional regulation of PNPLA3. Proc Natl Acad Sci U S A 2010;107:7892-7.

113. Hao L, Ito K, Huang KH, Sae-tan S, Lambert JD, Ross AC. Shifts in dietary carbohydrate-lipid exposure regulate expression of the 
non-alcoholic fatty liver disease-associated gene PNPLA3/adiponutrin in mouse liver and HepG2 human liver cells. Metabolism 2014;63:1352-62.

114. BasuRay S, Smagris E, Cohen JC, Hobbs HH. The PNPLA3 variant associated with fatty liver disease (I148M) accumulates on lipid droplets by evading ubiquitylation. Hepatology 2017;66:1111-24.

115. Nishioji K, Mochizuki N, Kobayashi M, et al. The impact of PNPLA3 rs738409 genetic polymorphism and weight gain $>/=10 \mathrm{~kg}$ after age 20 on non-alcoholic fatty liver disease in non-obese japanese individuals. PLoS One 2015;10:e0140427.

116. Honda Y, Yoneda M, Kessoku T, et al. Characteristics of non-obese non-alcoholic fatty liver disease: Effect of genetic and environmental factors. Hepatol Res 2016;46:1011-8.

117. Leung JC, Loong TC, Wei JL, et al. Histological severity and clinical outcomes of nonalcoholic fatty liver disease in nonobese patients. Hepatology 2017;65:54-64.

118. Fracanzani AL, Petta S, Lombardi R, et al. Liver and cardiovascular damage in patients with lean nonalcoholic fatty liver disease, and association with visceral obesity. Clin Gastroenterol Hepatol 2017;15:1604-11.e1.

119. Younossi ZM. Non-alcoholic fatty liver disease - a global public health perspective. J Hepatol 2019;70:531-44.

120. Fan Y, Lu H, Guo Y, et al. Hepatic transmembrane 6 superfamily member 2 regulates cholesterol metabolism in mice. Gastroenterology 2016;150:1208-18.

121. Kozlitina J, Smagris E, Stender S, et al. Exome-wide association study identifies a TM6SF2 variant that confers susceptibility to nonalcoholic fatty liver disease. Nat Genet 2014;46:352-6.

122. Liu YL, Reeves HL, Burt AD, et al. TM6SF2 rs58542926 influences hepatic fibrosis progression in patients with non-alcoholic fatty liver disease. Nat Commun 2014;5:4309.

123. Goffredo M, Caprio S, Feldstein AE, et al. Role of TM6SF2 rs58542926 in the pathogenesis of nonalcoholic pediatric fatty liver disease: a multiethnic study. Hepatology 2016;63:117-25.

124. Chen X, Zhou P, De L, Li B, Su S. The roles of transmembrane 6 superfamily member 2 rs 58542926 polymorphism in chronic liver disease: a meta-analysis of 24,147 subjects. Mol Genet Genomic Med 2019;7:e824.

125. Dongiovanni P, Petta S, Maglio C, et al. Transmembrane 6 superfamily member 2 gene variant disentangles nonalcoholic steatohepatitis from cardiovascular disease. Hepatology 2015;61:506-14.

126. Chen F, Esmaili S, Rogers GB, et al. Lean NAFLD: a distinct entity shaped by differential metabolic adaptation. Hepatology 2020;71:1213-27.

127. Adams LA, Marsh JA, Ayonrinde OT, et al. Cholesteryl ester transfer protein gene polymorphisms increase the risk of fatty liver in females independent of adiposity. J Gastroenterol Hepatol 2012;27:1520-7.

128. Musso G, Cassader M, Bo S, De Michieli F, Gambino R. Sterol regulatory element-binding factor 2 (SREBF-2) predicts 7-year NAFLD incidence and severity of liver disease and lipoprotein and glucose dysmetabolism. Diabetes 2013;62:1109-20.

129. Bale G, Vishnubhotla RV, Mitnala S, et al. Whole-exome sequencing identifies a variant in phosphatidylethanolamine N-methyltransferase gene to be associated with lean-nonalcoholic fatty liver disease. J Clin Exp Hepatol 2019;9:561-8.

130. Dong H, Wang J, Li C, et al. The phosphatidylethanolamine N-methyltransferase gene V175M single nucleotide polymorphism confers the susceptibility to NASH in Japanese population. J Hepatol 2007;46:915-20.

131. Song J, da Costa KA, Fischer LM, et al. Polymorphism of the PEMT gene and susceptibility to nonalcoholic fatty liver disease (NAFLD). FASEB J 2005;19:1266-71.

132. Nakatsuka A, Matsuyama M, Yamaguchi S, et al. Insufficiency of phosphatidylethanolamine N-methyltransferase is risk for lean nonalcoholic steatohepatitis. Sci Rep 2016;6:21721.

133. Yun Y, Kim HN, Lee EJ, et al. Fecal and blood microbiota profiles and presence of nonalcoholic fatty liver disease in obese versus lean subjects. PLoS One 2019;14:e0213692.

134. Machado MV, Cortez-Pinto H. Diet, microbiota, obesity, and NAFLD: a dangerous quartet. Int J Mol Sci 2016;17:481.

135. Ponziani FR, Bhoori S, Castelli C, et al. Hepatocellular carcinoma is associated with gut microbiota profile and inflammation in nonalcoholic fatty liver disease. Hepatology 2019;69:107-20.

136. Elshaghabee FMF, Bockelmann W, Meske D, et al. Ethanol production by selected intestinal microorganisms and lactic acid bacteria growing under different nutritional conditions. Front Microbiol 2016;7:47.

137. Elshaghabee FMF, Ghadimi D, Habermann D, et al. Effect of oral administration of weissella confusa on fecal and plasma ethanol concentrations, lipids and glucose metabolism in wistar rats fed high fructose and fat diet. Hepat Med 2020;12:93-106.

138. Koutnikova H, Genser B, Monteiro-Sepulveda M, et al. Impact of bacterial probiotics on obesity, diabetes and non-alcoholic fatty liver disease related variables: a systematic review and meta-analysis of randomised controlled trials. BMJ Open 2019;9:e017995.

139. Kwak JH, Jun DW, Lee SM, et al. Lifestyle predictors of obese and non-obese patients with nonalcoholic fatty liver disease: a crosssectional study. Clin Nutr 2018;37:1550-7.

140. Assy N, Nasser G, Kamayse I, et al. Soft drink consumption linked with fatty liver in the absence of traditional risk factors. Can $J$ Gastroenterol 2008;22:811-6.

141. Musso G, Gambino R, De Michieli F, et al. Dietary habits and their relations to insulin resistance and postprandial lipemia in nonalcoholic steatohepatitis. Hepatology 2003;37:909-16.

142. Bardella MT, Valenti L, Pagliari C, et al. Searching for coeliac disease in patients with non-alcoholic fatty liver disease. Dig Liver Dis 2004;36:333-6.

143. Emami MH, Hashemi M, Kouhestani S, Taheri H, Karimi S. Should we look for celiac disease among all patients with liver function test abnormalities? Int J Prev Med 2012;3:167-72. 
144. Bakhshipour A, Kaykhaei MA, Moulaei N, Mashhadi MA. Prevalence of coeliac disease in patients with non-alcoholic fatty liver disease. Arab J Gastroenterol 2013;14:113-5.

145. Rahimi AR, Daryani NE, Ghofrani H, et al. The prevalence of celiac disease among patients with non-alcoholic fatty liver disease in Iran. Turk J Gastroenterol 2011;22:300-4.

146. Bargiggia S, Maconi G, Elli M, et al. Sonographic prevalence of liver steatosis and biliary tract stones in patients with inflammatory bowel disease: study of 511 subjects at a single center. J Clin Gastroenterol 2003;36:417-20.

147. Tovoli F, Negrini G, Fari R, et al. Increased risk of nonalcoholic fatty liver disease in patients with coeliac disease on a gluten-free diet: beyond traditional metabolic factors. Aliment Pharmacol Ther 2018;48:538-46.

148. Reilly NR, Lebwohl B, Hultcrantz R, Green PH, Ludvigsson JF. Increased risk of non-alcoholic fatty liver disease after diagnosis of celiac disease. J Hepatol 2015;62:1405-11.

149. Abenavoli L, Milic N, De Lorenzo A, Luzza F. A pathogenetic link between non-alcoholic fatty liver disease and celiac disease. Endocrine 2013;43:65-7.

150. van Zutphen T, Ciapaite J, Bloks VW, et al. Malnutrition-associated liver steatosis and ATP depletion is caused by peroxisomal and mitochondrial dysfunction. J Hepatol 2016;65:1198-208.

151. Machado MV, Cortez-Pinto H. Insulin resistance and steatosis in chronic hepatitis C. Ann Hepatol 2009;8 Suppl 1:S67-75.

152. HH AK. Lysosomal acid lipase deficiency: a form of non-obese fatty liver disease (NOFLD). Expert Rev Gastroenterol Hepatol 2017;11:911-24.

153. Reynolds TM, Mewies C, Hamilton J, Wierzbicki AS, group PPC. Identification of rare diseases by screening a population selected on the basis of routine pathology results-the PATHFINDER project: lysosomal acid lipase/cholesteryl ester storage disease substudy. $J$ Clin Pathol 2018;71:608-13.

154. Khoury J, Zohar Y, Shehadeh N, Saadi T. Glycogenic hepatopathy. Hepatobiliary Pancreat Dis Int 2018;17:113-8.

155. Welty FK. Hypobetalipoproteinemia and abetalipoproteinemia: liver disease and cardiovascular disease. Curr Opin Lipidol 2020;31:49-55.

156. Noto D, Arca M, Tarugi P, Cefalu AB, Barbagallo CM, Averna MR. Association between familial hypobetalipoproteinemia and the risk of diabetes. Is this the other side of the cholesterol-diabetes connection? A systematic review of literature. Acta Diabetol 2017;54:111-22.

157. Pelusi S, Baselli G, Pietrelli A, et al. Rare pathogenic variants predispose to hepatocellular carcinoma in nonalcoholic fatty liver disease. Sci Rep 2019;9:3682.

158. Dela Cruz ACD, Bugianesi E, George J, et al. Characteristics and long-term prognosis of lean patients with nonalcoholic fatty liver disease: international follow up study. Gastroenterology 2014;146:A379.

159. Shao C, Ye J, Li F, Feng S, Wang W, Zhong B. Different predictors of steatosis and fibrosis severity among lean, overweight and obese patients with nonalcoholic fatty liver disease. Dig Liver Dis 2019;51:1392-9.

160. Hagstrom H, Nasr P, Ekstedt M, et al. Risk for development of severe liver disease in lean patients with nonalcoholic fatty liver disease: a long-term follow-up study. Hepatol Commun 2018;2:48-57.

161. Alam S, Gupta UD, Alam M, Kabir J, Chowdhury ZR, Alam AK. Clinical, anthropometric, biochemical, and histological characteristics of nonobese nonalcoholic fatty liver disease patients of Bangladesh. Indian J Gastroenterol 2014;33:452-7.

162. Denkmayr L, Feldman A, Stechemesser L, et al. Lean patients with non-alcoholic fatty liver disease have a severe histological phenotype similar to obese patients. J Clin Med 2018;7.

163. Akyuz U, Yesil A, Yilmaz Y. Characterization of lean patients with nonalcoholic fatty liver disease: potential role of high hemoglobin levels. Scand J Gastroenterol 2015;50:341-6.

164. Yilmaz Y, Senates E, Ayyildiz T, et al. Characterization of nonalcoholic fatty liver disease unrelated to the metabolic syndrome. Eur $J$ Clin Invest 2012;42:411-8.

165. Fukuda T, Hamaguchi M, Kojima T, et al. The impact of non-alcoholic fatty liver disease on incident type 2 diabetes mellitus in nonoverweight individuals. Liver Int 2016;36:275-83.

166. Golabi P, Paik J, Fukui N, Locklear CT, de Avilla L, Younossi ZM. Patients with lean nonalcoholic fatty liver disease are metabolically abnormal and have a higher risk for mortality. Clin Diabetes 2019;37:65-72.

167. European Association for the Study of the L, European Association for the Study of D, European Association for the Study of O. EASLEASD-EASO Clinical Practice Guidelines for the management of non-alcoholic fatty liver disease. J Hepatol 2016;64:1388-402.

168. Alam S, Jahid Hasan M, Khan MAS, Alam M, Hasan N. Effect of weight reduction on histological activity and fibrosis of lean nonalcoholic steatohepatitis patient. $J$ Transl Int Med 2019;7:106-14.

169. Albu JB, Heilbronn LK, Kelley DE, et al. Metabolic changes following a 1-year diet and exercise intervention in patients with type 2 diabetes. Diabetes 2010;59:627-33.

170. Ohkawara K, Tanaka S, Miyachi M, Ishikawa-Takata K, Tabata I. A dose-response relation between aerobic exercise and visceral fat reduction: systematic review of clinical trials. Int J Obes (Lond) 2007;31:1786-97.

171. Ismail I, Keating SE, Baker MK, Johnson NA. A systematic review and meta-analysis of the effect of aerobic vs. resistance exercise training on visceral fat. Obes Rev 2012;13:68-91. 